\title{
Development and Application of Rice Starch Based Edible Coating to Improve the Postharvest Storage Potential and Quality of Plum Fruit (Prunus salicina)
}

R. Thakur, P. Pristijono, J. B. Golding, C. E. Stathopoulos, C. J. Scarlett, M. Bowyer, S.P. Singh, Q. V. Vuong

This is the accepted manuscript $@$ 2016, Elsevier

Licensed under the Creative Commons Attribution-NonCommercial-

NoDerivatives 4.0 International: http://creativecommons.org/licenses/by$\underline{\text { nc-nd/4.0/ }}$

\section{(c) EY-No-ND}

The published article is available from doi:

10.1016/i.scienta.2018.04.005 
1 Development and Application of Rice Starch Based Edible Coating to Improve the

2 Postharvest Storage Potential and Quality of Plum Fruit (Prunus salicina)

3 R. Thakur ${ }^{a^{*}}$, P. Pristijono ${ }^{\text {a }}$, J. B. Golding ${ }^{\text {a, c }}$, C. E. Stathopoulos ${ }^{\text {b }}$, C. J. Scarlett ${ }^{\text {a }}$, M.

4 Bowyer $^{\text {a, }}$, S.P. Singh ${ }^{\text {a, c }}$, Q. V. Vuong ${ }^{\text {a* }}$

$5{ }^{\text {a }}$ School of Environmental and Life Sciences, University of Newcastle, Ourimbah, NSW $6 \quad 2258$, Australia

$7 \quad{ }^{b}$ Division of Food and Drink, School of Science, Engineering and Technology, University of 8 Abertay, Dundee DD1 1HG, UK

$9 \quad{ }^{\mathrm{c}}$ NSW Department of Primary Industries, Ourimbah, NSW 2258, Australia

*Correspondence to:

R. Thakur

E mail: Rahul.thakur@uon.edu.au

17 School of Environmental and Life Sciences, Faculty of Science and Information Technology,

18 University of Newcastle, Brush Road, Ourimbah, NSW 2258, Australia.

19 Q. V. Vuong

20 School of Environmental and Life Sciences, Faculty of Science and Information Technology,

21 University of Newcastle, Brush Road, Ourimbah, NSW 2258, Australia.

22 Email: vanquan.vuong@newcastle.edu.au 


\section{Abstract}

The study investigated the possibility of enhancing the shelf life of plum fruit coated with rice starch-1-carrageenan (RS-1-car) composite coating blended with sucrose fatty acid esters (FAEs). Film solution (starch 3\%, carrageenan 1.5\% and FAEs 2\%) was prepared by mixing the ingredients and properties of stand-alone films (physical, mechanical, barrier and surface morphology) were studied before applying the coating on fruit surface. Fruit were stored at $20^{\circ} \mathrm{Cfor} 3$ weeks and analyzed for weight loss, ethylene production, respiration rate, color change, firmness, and titratable acidity (TA) and soluble solid content (SSC). Surface morphology of stand-alone film and fruit surface (after applying on the plum fruit) was studied using scanning electron microscopy (SEM). Phytochemical analysis was performed during the storage period and total phenolic content (TPC), total antioxidant capacity (TAC), flavonoid content (FC) and free radical scavenging activity were determined. The rice starch composite coating was shown to be effective in reducing both weight loss (WL) and respiration rate and inhibiting the endogenous ethylene production when compared to the uncoated control fruit stored at room temperature $(p<0.05)$. TPC, TAC, FC and free radical scavenging activity was unaffected in the coated fruit throughout the storage period $(p<0.05)$. The findings reported in this study indicate that the RS-1-car-FAEs coating prolongs the shelf life and maintains the overall quality of plum fruit during storage and could potentially be commercialized as a new edible coating for the plum fruit industry.

Keywords: Starch; Coating; Plum; Fruit; Postharvest; Shelf-life 


\section{Introduction}

48

Plum is considered a climacteric fruit (Wu et al., 2011) that softens rapidly during the postharvest supply chain due to rapid senescence. Fruit softening is a natural phenomenon that progresses with storage and compromises final fruit quality leading to significant volumes of fruit being rejected at the marketplace due to firmness levels being below acceptable retail standards (Hussain et al., 2015; Paniagua et al., 2013). Therefore, new research aimed at improving the postharvest shelf life and storage quality of plum fruit is necessary and has great potential value for plum industry.

Plum is an important commercial stone fruit, grown in different geographical regions globally. Worldwide annual production currently exceeds 10 million tons (Karaca et al., 2014). A number of previous studies have shown low temperature storage and al., 2015; Kumar et al., 2017; Pan et al., 2018). However, this method of preservation often results into severe chilling injury, translucency and red pigment accumulation (bleeding) and flavor loss (Minas et al., 2013). Other techniques have been studied to improve the postharvest life of plum fruit including edible surface coatings, modified atmosphere packaging, fumigation with ethylene antagonists such as 1-MCP, salicylic acid treatment and natural signaling agents such as nitric oxide (Liu et al., 2014; Manjunatha et al., 2010; Pan et al., 2016; Singh et al., 2009). The use of edible films and coatings has recently emerged as an innovative and effective solution to extending the shelf life of fresh horticulture produce. These surface coatings extend postharvest life by regulating gaseous exchange and slowing moisture loss through the formation of cohesive molecular semipermeable network covering the fruit surface (Vargas-Torres et al., 2017). Edible coatings can also improve the texture quality of fruit (Choi et al., 2016; Karaca et 
al., 2014) and reduce the incidence of skin bruising during handling. Novel coating materials previously utilised on plums include chitosan (Kumar et al., 2017), hydroxypropylmethyl cellulose (Choi et al., 2016), aloe vera (Guillén et al., 2013), xanthan and gellan gums and sodium alginate (Vargas-Torres et al., 2017). However, these combinations still have permeability and tensile strength limitations in improving the postharvest quality of plum fruit and new, more compatible biopolymer coating materials therefore need to be developed to overcome the current limitations.

Rice starch is an underutilized conventional biodegradable material that has not previously been explored alone or in combination with other compatible biopolymers for 


\section{Materials and methods}

97

98

99

100

101

102

103

104

105

106

107

108

109

110

111

112

113

114

115

116

117

118

\subsection{Materials}

Rice grains (Oryza sativa var. Doongara) were obtained from Sunrice (Sun Rice, Leeton Australia). The 1-carrageenan (Chondrus crispus) was purchased from Melbourne Food ingredient depot, Victoria, Australia. Glycerol (Ajax fine-chem Pty. Ltd, Australia) was used as plasticizing agent in the film formulation. Starch isolation and characterisation of its chemical composition is described elsewhere (Thakur et al., 2016). Sucrose fatty acid ester was purchased from Xi'an Plant Bio-Engineering Co., Ltd, China.

\subsection{Preparation of film/coating solution}

Based on the laboratory trials and preliminary study, the optimum volume required to coat the fruit was identified and used for subsequent coating experiment. Rice starch $(3 \%, \mathrm{w} / \mathrm{w})$, t-car $(1.5 \%, \mathrm{w} / \mathrm{w})$, FAEs $(2 \% \%, \mathrm{w} / \mathrm{w})$ and glycerol $(1 \%, \mathrm{w} / \mathrm{w})$ were mixed in a two-step procedure. In the first step, starch solution (2\%) was prepared by heating a starch-water mixture at $85{ }^{\circ} \mathrm{C}$ using a hot plate magnetic stirrer for $15 \mathrm{~min}$. In the second step l-car gelling solution was prepared by heating the $1-\mathrm{car}-\mathrm{H}_{2} \mathrm{O}$ mixture at $80^{\circ} \mathrm{C}$ for 20 min. until a clear transparent gel was formed. The solution from step 1 and step 2 were mixed together with a subsequent addition of FAEs and glycerol and stirred for a further $20 \mathrm{~min}$.

2.2.1 Formation of edible film: The final film solution $(20 \mathrm{~mL})$ was poured into Petri plates and dried in the oven for $24 \mathrm{~h}$ under controlled conditions $\left(35^{\circ} \mathrm{C}, \mathrm{RH} 50 \%\right)$. For evaluation, dried films were peeled from the plate surface and dried in a desiccator prior to the final thickness being determined. For water vapor permeability measurement, films (three replication with six films each) were conditioned at $27^{\circ} \mathrm{C}, \mathrm{RH} 60 \%$ for $72 \mathrm{~h}$ prior to measurement. 


\subsection{Properties of rice starch-ı-car film}

\subsubsection{Thickness, water vapour permeability (WVP) and tensile properties}

121 Thickness of film was measured using a digital micro-meter (Mitutoyo, Co., Code No. 543551-1, Model ID-F125, 139 Japan; sensitivity=0.001 mm). Ten measurements were taken from random positions for each film samples and mean value calculated to analyse WVP and optical properties. WVP was measured according to a previously reported method by Thakur et al. (2016). Tensile strength (TS) and elongation at break (EAB) were determined using a Texture Analyzer (LLOYD Instrument LTD, Fareham, UK). Preconditioned (60\% RH) films $(15 \times 40 \mathrm{~mm})$ were placed in the tensile grip with initial grip distance $40 \mathrm{~mm}$ and $1 \mathrm{~mm} / \mathrm{s}$ crosshead speed. Ten samples from every single film preparation were studied for the mechanical properties of the film.

\subsection{Fruit coating and design of experiment}

Mature plum fruit (Prunus salicina) without visual defects, were collected from a local market (Central AVE. Shepparton East, NSW, Australia) and coated on the same day of purchase. A randomized experimental design, comprising 60 homogeneous lots (based on color and size) of 7 fruit each were assembled randomly. Four lots were used to measure the fruit properties at harvest ( 0 day) and the remaining 56 lots were divided into two groups for the following treatments in four replicates i.e., four lots (with 7 fruit per replication) from each treatment were assessed on the sampling day for the different properties. Two treatments, coated (rice starch-1-carrageenan-FAEs) and control (without any coating) were used in this experiment and treated accordingly. For coating: cooled emulsion $(0.5 \mathrm{~mL})$ was applied over the individual fruit using hand coating method ensuring the whole surface of the fruit including calyx and epicalyx were coated uniformly. The coatings were then dried using hair dryer placed at a distance of $60 \mathrm{~cm}$ from the fruit to avoid thermal damage. After drying, 
the fruit were stored at $20^{\circ} \mathrm{C} / \mathrm{RH} 55 \pm 5 \%$ and their quality monitored every third day to assess the effectiveness of applied coating on physiological parameters.

\subsubsection{Measurement of plum ethylene and respiration rate}

Plum fruit, $(\mathrm{n}=4)$ from each replicate were sealed in a $0.5 \mathrm{~L}$ hermetic glass jar (2 fruit per jar, selected randomly) with a septum and a lid for gas sampling after $2 \mathrm{~h}$. The jars were stored at ambient temperature of $20^{\circ} \mathrm{C}$ and gas sampling was carried out using a needle probe through the rubber septum. After $2 \mathrm{~h}$ incubation, a sample of headspace gas was used to measure the rate of $\mathrm{CO}_{2}$ production. For ethylene measurement, $1 \mathrm{~mL}$ of gas sample was withdrawn from the vessel and inserted into a gas chromatograph (Gow-Mac 580, Bridgewater NJ) fitted with a 6' x 1/8',activated alumina stainless steel carbowax silico steel 80/100 column and equipped with a flame ionization detector. Nitrogen was used as the carrier gas for all experiments. The injector, column and detector temperatures were set at $65^{\circ} \mathrm{C}, 85^{\circ} \mathrm{C}$ and 105

${ }^{\circ} \mathrm{C}$ respectively. The ethylene production rate was expressed in $\mu \mathrm{L} \mathrm{C}_{2} \mathrm{H}_{4} / \mathrm{kg} \mathrm{h}$ and calculated as.

Ethylene rate $\left(\mu \mathrm{L} \mathrm{C}_{2} \mathrm{H}_{4} / \mathrm{kg} \mathrm{h}\right)=C_{2} H_{4}\left(\mu \mathrm{L} L^{-1}\right) x$ volume $(\mathrm{mL}) /$ weight $(\mathrm{kg}) x$ time $(h)$

The respiration rate was determine by measuring $\mathrm{CO}_{2}$ in $5 \mathrm{~mL}$ of gas sample withdrawn from the vessel and injected into a using an ICA40 series low-volume gas analysis system (International Controlled Atmosphere Ltd., Kent, UK). Respiration rate was calculated using the following equation:

$\mathrm{CO}_{2}\left(\mathrm{ml} \mathrm{Kg}^{-1} \mathrm{~h}^{-1}\right)=\left(\mathrm{CO}_{2}(\%) x\right.$ volume $(\mathrm{mL}) /($ weight $(\mathrm{kg}) x$ time $(\mathrm{h}) \times 100)$

\subsubsection{Measurement of plum firmness}

The flesh firmness of starch uncoated and coated plums was measured using HortPlus ${ }^{\mathrm{TM}}$ Penetrometer after 0 day, days $3,6,9,12,15,18$ and 21 days storage at $20{ }^{\circ} \mathrm{C}$. The average 
of two readings from each side of the fruit was recorded. For measuring the fruit firmness,

167 fruit skin $(1 \mathrm{x} 1 \mathrm{~cm})$ was peeled off using a sharp knife to expose the flesh from two ends one opposite to each other. A $7 \mathrm{~mm}$ diameter stainless steel probe was inserted into the fruit and corresponding values were recorded using computer software. The maximum penetration

170 force $(\mathrm{N})$ was defined as the maximum force required pushing the probe into the plum surface to a depth of $2 \mathrm{~mm}$ at a cross-head speed of $1 \mathrm{~mm} / \mathrm{s}$.

\subsubsection{Weight loss}

The weight loss (\%) was determined by weighing the plum fruit before and after the storage

174 period

\subsubsection{Measurement of color change}

The color of the plum surface was determined by a Chroma meter CR-400 (Konica Minolta Sensing Inc., Japan). The CIELAB software was employed to measure the L*, a*, and $b *$ values.

\subsubsection{TSS and TA}

For the assessment of total soluble solids (TSS) and titratable acidity (TA), fruit samples were chopped into small pieces and squeezed until no more juice was released. TSS was determined with a digital hand-held refractometer (Atago PAL-1, Japan). TA was determined by titrating $5 \mathrm{~mL}$ of juice with $0.05 \mathrm{M} \mathrm{NaOH}$ to $\mathrm{pH} 8.2$ using an automatic titrator (Mettler Toledo T50, Switzerland) and the result was expressed as a percentage of malic acid.

\subsection{Surface morphology (SEM)}

Stand-alone film and fruit surface morphology were studied by using scanning electron microscope (JEOL, JSM 6300 SEM, JEOL, and Tokyo, Japan). Film samples were stored in 
desiccator for 1 week to ensure the dryness (theoretical RH in desiccator $0 \%$ ). For fruit, samples were freeze dried completely and stored in the desiccator prior to analysis. The microscopic analysis of film and fruit was determined by mounting the sample pieces on the copper stubs, gold coated and observed using an accelerating voltage of $10 \mathrm{kV}$ under high vacuum mode.

\subsection{Polyphenols determination}

\subsubsection{Determination of total polyphenolic content (TPC)}

A modified Folin-Ciocalteu method as described by (Bhuyan et al., 2015) was used for the determination of total polyphenolic content (TPC). Briefly, diluted juice sample ( $1 \mathrm{ml}$ of fruit juice in $50 \mathrm{~mL}$ of water) was mixed with $5 \mathrm{~mL}$ of Folin-Ciocalteu reagent and $4 \mathrm{~mL}$ of $7.5 \%$ $\mathrm{Na}_{2} \mathrm{CO}_{3}$ solution. The mixture was left at room temperature for $1 \mathrm{~h}$ to complete the reaction. The optical absorbance was measured at $765 \mathrm{~nm}$ using UV-spectrophotometer (Varian Australia Pty. Ltd., Victoria, Australia). A calibration curve $\left(\mathrm{R}^{2}\right.$ 0.998) was constructed with ten points using Gallic acid as a pure standard. The results expressed as gallic acid equivalents (GAE) mg GAE $\mathrm{mL}^{-1}$ of fresh fruit juice sample.

\subsubsection{Total flavonoids content (TFC)}

The total flavonoid content was measured by $\mathrm{AlCl}_{3}$ colorimetric assay as described by Šamec et al. (2016) with some modifications. Briefly, to $0.5 \mathrm{~mL}$ of diluted sample $2 \mathrm{~mL}$ of $\mathrm{H}_{2} \mathrm{O}$ and $0.15 \mathrm{~mL}$ of $5 \%(\mathrm{w} / \mathrm{v}) \mathrm{NaNO}_{2}$ were added and left at RT for 6 minutes. Then, $0.15 \mathrm{~mL}$ of $10 \%$ (w/v) $\mathrm{AlCl}_{3}$ was added and left at $\mathrm{RT}$ for another 6 minutes. It was followed by the addition of $2 \mathrm{~mL}$ of $4 \%(w / v) \mathrm{NaOH}$ and $0.7 \mathrm{~mL}$ of $\mathrm{H}_{2} \mathrm{O}$ with the final solution being mixed well and left at RT for a further 15 minutes before the absorbance was measured at $510 \mathrm{~nm}$ using a UV 
spectrophotometer. Rutin was used as the standard for a calibration curve $\left(R^{2} 0.994\right)$ and the results were expressed rutin equivalents (mg RUE $\mathrm{mL}^{-1}$ of juice sample).

\section{7 Determination of antioxidant capacity}

\section{7.1 DPPH radical scavenging activity determination and cupric acid antioxidant} capacity (CUPRAC)

The DPPH (1,1-diphenyl-2-2picrylhydrazyl) radical scavenging activity and the antioxidant capacity of the plum fruit samples was determined using the assays described previously (Bhuyan et al., 2015; Jatoi et al., 2017). Briefly, $1 \mathrm{~mL}$ of $10 \mathrm{mM} \mathrm{CuCl}_{2} \cdot 2 \mathrm{H}_{2} \mathrm{O}$ was mixed with $1 \mathrm{~mL}$ of $7.5 \mathrm{mM}$ neocuproine solution and $1 \mathrm{M} \mathrm{NH}_{4} \mathrm{CH}_{3} \mathrm{COO}$ solution. Filtered juice sample $(0.5 \mathrm{~mL})$ was added to the above solution and final volume was completed to $4.1 \mathrm{~mL}$ with pure distilled water. The solution was let to stand at room temperature for $1.5 \mathrm{~h}$ to achieve equilibrium. Absorbance measurements of the resulting cuprous-neocuproine complex was measured at $450 \mathrm{~nm}$ against a reagent blank. Trolox was used as standard and results expressed as millimole Trolox equivalent (mg TE $\mathrm{mL}^{-1}$ juice sample).

\subsection{Statistical analysis}

Analysis of variance (ANOVA) was performed on the test data by using the SPSS software package, v. 24.0 for Windows (SPSS, Inc., Chicago, IL). Analyses of films samples were carried out in triplicate. For the fruit quality assessment, fruit samples with four replications including seven fruit per replications were used. Tukey's test was used to examine whether the differences among the treatments were significant at $p<0.05$. 


\section{Results and discussion}

231

232 The evaluation of coating performance under in vitro conditions (on the fruit surface) is necessary to assess their performance characteristics for future industrial applications. It is

234 however, equally important to understand the physical and chemical behavior of coating 235 formulations as standalone entities in order to be able to adapt to the commercial requirements. Film thickness, tensile strength, adhesion and gas an moisture exchange characteristics may affect the coating integrity during the prolonged storage of fresh horticulture produce, therefore, films prepared from rice starch-1-car-FAEs composite material were analyzed for physical, mechanical and barrier properties.

The results showed that the final casted film has an average thickness of $0.07 \mathrm{~mm}$, tensile strength $253.5 \mathrm{~N} / \mathrm{m}^{2}$, EAB $35 \mathrm{~mm}$ and WVP $2.8 \times 10^{-11} \mathrm{gs}^{-1} \mathrm{~m}^{-1} \mathrm{~Pa}^{-1}$ respectively. Compared to the properties of a standalone film, actual coating performance is affected by coating distribution over the fruit surface for example whether it forms a continuous uniform layer over the fruit surface (Fagundes et al., 2015). Therefore, film morphology becomes more important aspect of the analyses of film surface features. SEM images of the manufactured films showed no solid granule remnants or aggregates within their structure, indicating high

247 miscibility of the formulation ingredients (Fig 1). A recent study by Huc et al. (2014) reported favorable miscibility between polysaccharides and carrageenan molecules to result from the formation of a strong networking complex arising from the incorporation of carrageenan strands into the helical structures of amylose and amylopectin. RS-l-car-FAEs films showed smooth surfaces, free of defect (pores or cracks) and no sign of phase separation. The smooth surface further reflects the stronger inter- and intra- molecular interactions between the components. In summary, these morphological observations confirm 
that rice starch-1-car-FAEs composite combination resulted in a strong semi-permeable membrane with a uniform distribution over the fruit surface.

256

257

\subsection{Analytical determinations}

\subsubsection{Weight loss (WL) (\%)}

Moisture loss is an important aspect of storage and is driven by a difference in water vapour pressure between the fruit surface and the environment (Brasil and Siddiqui, 2018). Rice-1car-FAEs treatment employed in this study showed a significant impact on the weight loss of plum fruit during the three weeks storage period (Fig 2). As expected, weight loss increased during storage for both control and coated fruit. The control fruit showed higher weight loss $(1 \%)$ compared to coated fruit $(<0.8 \%)$ during 21 days of storage. The reduction in the weight loss in the coated fruit was attributed to the beneficial effect of the polysaccharides-based edible coating, and has previously been demonstrated to be effective in a wide range of commercial fruit including mango, pomegranate, pineapple and strawberry (Bierhals et al., 2011; Chiumarelli et al., 2010; García et al., 2001). The complex network formed between the starch-FAEs and starch with other ingredients retarded the mass loss in the plum fruit. Loss of water vapour from the fruit surface is a natural aspect of fruit metabolic processes that occur through the pores and cracks on skin. From the SEM micrographs (Fig 1) it is clear that there were some cracks at the fruit surface in the uncoated fruit which might have facilitated accelerated moisture and weight loss. In the coated fruit, the coating covers the pores and cracks, thereby limiting transpiration while allowing gaseous exchange to continue $\left(\mathrm{WVP}=2.8 \times 10^{-11} \mathrm{gs}^{-1} \mathrm{~m}^{-1} \mathrm{~Pa}^{-1}\right)$. Loss of moisture from the control fruit surface can also be explained as a poor function of cuticle wax layer, which might have lost its integrity during washing and handing thus unmasking the skin pores at some areas. Respiration has also been considered as an important factor behind the weight loss. The heat generated during the respiration process leads to temperature elevation within the fruit which in turn increases 
internal water vapor pressures leading to increased transpiration. Moreover, a strong correlation $\left(\mathrm{R}^{2} 0.86 \%\right)$ exists between weight loss and respiration signifying that increased respiration rate has contributed in the weight loss throughout the storage period.

\subsubsection{Ethylene production rate}

Endogenous ethylene production is a primary characteristic of ripening in climacteric fruit. Fig 3 shows the rate of ethylene production for uncoated and coated fruit during the three weeks storage period at ambient temperature $\left(20^{\circ} \mathrm{C}\right)$. A significant increase $(p<0.05)$ in the ethylene production was observed from the first week (from 0.03 to $9.76 \mu \mathrm{L} \mathrm{C}_{2} \mathrm{H}_{2} / \mathrm{Kg} / \mathrm{h}$ ) which was $8.08 \mu \mathrm{L} \mathrm{C}_{2} \mathrm{H}_{2} / \mathrm{Kg} / \mathrm{h}$ higher than coated fruit at the end of storage. These effects were similar to those obtained with other edible coatings (Martínez-Romero et al., 2017; Pan et al., 2016). Biosynthesis of ethylene occurs as ripening progresses in the fruit and is regulated by ripening enzyme 1-aminocyclopropane-1-carboxylic acid (ACC) synthase and oxidase. ACC synthase convert the ACC into S-adenosyl-methionine (SAM) to ACC which is subsequently converted to ethylene via the action of a second enzyme - ACC oxidase. (Wills and Golding, 2016). The decreased levels of ethylene expressed by the coated fruit signify that coating has provided an effective gas barrier between the fruit and the surrounding atmosphere. The semi anaerobic conditions formed inside the fruit might have decreased the catalytic activity of ACC oxidase thus the ethylene production was effectively maintained by the coated fruit during the storage (Both et al., 2016; Deng et al., 2017).

\subsubsection{Firmness}

Flesh firmness is one of the most noticeable physical changes used to assess the quality of the fresh produce and is closely aligned to the rate of water loss as well as metabolic changes within the fruit including loss of membrane integrity, hydrolysis of cellulose and 
hemicellulose as well as depolymerisation of pectin and starch (Mditshwa et al., 2017). Flesh

305 firmness in the control fruit declined continuously during the storage period (Fig 4a),

306 decreasing from $2.25 \mathrm{~N}$ (Day 3) to $0.05 \mathrm{~N}$ (Day 21). Across the same storage period, firmness

307 in the coated fruit remained consistently greater than the control $(p<0.05)$, indicating that the

308 starch composite coating had significant, beneficial impact on fruit quality. The semi309 permeability of membrane in the coated fruit restricted metabolic gas exchange $\left(\mathrm{O}_{2}\right.$ and $\left.\mathrm{CO}_{2}\right)$

310 through the coating barrier, resulting in a slowdown in metabolic activity including the

311 effectiveness of oxidizing enzymes leading to retention of firmness. The differential in the

312 rate of tissue softening between treated and control fruit was greatest during the third week of

313 storage and is consistent with previously findings by Tesfay and Magwaza (2017) and

314 Mahfoudhi and Hamdi (2015) who concluded that oxidizing enzymes (of polygalacturonase,

$315 \beta$-galactosidase and pectin methyl esterase) play a significant role in maintaining the firmness

316 of the coated fruit. The activity of these enzymes could be suppressed by the internal low $\mathrm{O}_{2}$

317 concentration in case of the coated fruit. Another important parameter that affects the fruit

318 firmness is the loss of water during storage. Firmness results are supported by fruit weight

319 loss \% which was higher in the control fruit $\left(\mathrm{R}^{2}\right.$ 0.91) (Fig 4b). Similar results were observed

320 (Paniagua et al., 2013) who found that fruit firmness and softening is influenced by

321 transpiration induced moisture loss. Water loss as a form of stress has the potential to elicit

322 senescence like response, which may also explain or contribute to the induced firmness

323 changes in these studies. 


\subsubsection{Respiration rate}

326 Atmospheric gases, particularly $\mathrm{O}_{2}$, serve as a crucial substrate of many biochemical reactions in the fruit (Dongen and Licausi, 2015). The respiration rate for control and coated fruit is presented in Fig 5 and shows that the treatment apparently suppressed the respiration rate during storage. In general fruit metabolic process, higher the energy metabolism rate (respiration), more quickly will be the consumption of nutrients and faster the ripening rate.

Differences in the respiration rate of the fruit reveal that coating was a sensitive indicator for the gas exchange abilities of edible coating. Permeability of gases is a function of Fick's law of diffusion and Henry's law of solubility and can be used to express the steady state permeability of a permeate through a non-porous barrier of known thinness, hence the need to design films critically with the thickness as low as possible (Thakur et al., 2017). An impermeable coating will prevent the fruit respiration process and cause anaerobic conditions that leads to the accumulation of off-flavor volatiles (Arnon et al., 2015). On the other hand, a film with high permeability will not sufficiently modify the atmosphere to retard the respiration (Baldwin et al., 1999). Respiration rate was lower than control fruit throughout the storage period however no statistical difference was observed until 18D $(p>0.05)$. The possible fluctuations in the respiration graph could be due to the fact that true equilibrium of gases between system (fruit) and surrounding was hard to achieve since the fruit were continuously ripening. It is interesting to note that control and coated fruit undergo an abrupt increase during the $3^{\text {rd }}$ week of storage from 24.99 to $45.09 \mathrm{mLCO}_{2} \mathrm{Kg}^{-1} \mathrm{~h}^{-1}$ and 22.06 to $30.85 \mathrm{mLCO}_{2} \mathrm{Kg}^{-1} \mathrm{~h}^{-1}$ and a significant difference was observed in the control and coated fruit $(p<0.05)$. The most possible reason for this trend could be the widening of stomatal pores due to the rapid process of ripening leading the fruit to consume more oxygen. However, no such information related to this event is available in the literature hence further study is recommended to understand the behavior of plum respiration rate under the conditions 
experimented in this experiment. In summary, the slow rate of fruit respiration combined with relatively low concentration of $\mathrm{CO}_{2}$ was observed due to the modified atmosphere created by the coating over the fruit surface.

\subsubsection{SSC \& TA}

Sugars represent a fundamental component of fruit edible quality, predominantly conferring sweetness and importantly influencing the consumer satisfaction for plum fruit. Organic acids, as a respiratory substrate, begin degrading as ripening progresses, resulting in increased sugar loading (Kowalczyk et al., 2017). As shown in the Fig 6, no significant difference $(p>0.05)$ between the SSC content of the control and coated fruit was observed during the storage period, signifying no negative impact of the coating material. From the titratable acidity results shown in Fig $6 b$, it could be seen that no significant difference between the treated and control fruit was observed $(p>0.05)$ however, there was an overall decrease in TA values during 3 weeks of storage period. The decrease in TA during postharvest storage of plums has been attributed to the use of organic acids as substrate for the respiratory metabolism in the fruit (Valero et al., 2013).

\subsubsection{Color}

In the process of ripening and senescence, plum fruit color changes from light red to dark red due to the biosynthesis of anthocyanins. The variations in fruit skin color as represented by the hue angle and shown in Fig 7. Starch coating delayed the synthesis of anthocyanin in control and coated fruit without any significant differences between them $(p>0.05)$. The possible reason for the lower value of hue ${ }^{\mathrm{o}}$ in the coated fruit could be the suppressed metabolic activities that ultimately led to the inhibition of anthocyanin synthesis. Similar 
explanation has been provided by earlier by Valero et al. (2013) who reported that edible coating delayed the color development in plum fruit.

\subsubsection{Total phenolic content}

Phenolic compounds are synthesized during maturation as secondary metabolites; however they are also synthesized during the ripening of fruit (Andrade et al., 2017). Table 1 shows the phytochemical profile of coated and control fruit analyzed on different sampling time stored for 21 days. From the data it is clear that concentrations of phenolic compounds generally decreased with the storage time regardless of the treatment. However, starch coating suppressed the decline in the phenolic content during storage. The concentration of phenolic compounds for the uncoated plums was markedly reduced for first $6 \mathrm{~d}(1.14 \mathrm{mg}$ GAE. $\mathrm{ml}^{-1}$ juice) showing lowest concentration of phenolic compounds among the fruit. The decrease in the phenolic components at the end of storage could be due to the cell structural breakdown as a part of senescence during storage. Similar explanation has been provided in previous reported studies (Ghasemnezhad et al., 2013; Nadim et al., 2015) for decrease in total phenolic content in the fruit. (Kim et al., 2013) explained the activities of phenol oxidase and peroxidase for the decrease in phenolic content for the plum fruit. However, the concentration reaches to its higher content (1.74 mg GAE. ml ${ }^{-1}$ juice) at the end of $12 \mathrm{~d}$ and started declining when stored further. The phenolic content was higher in the coated plums during the first and last week of storage however no statistical significant differences were observed between control and coated fruit $(p>0.05)$. The total flavonoids content of control and coated fruit was between 16.98 to $27.09 \mathrm{mg} \mathrm{RT}$. $\mathrm{ml}^{-1}$ and 17.75 to $34.80 \mathrm{mg} \mathrm{RT}$. $\mathrm{ml}^{-1}$ juice respectively (Table 1). For coated fruit, flavonoid content was higher at the end of storage period however no significant difference $(\mathrm{p}>0.05)$ was observed among the treated and untreated fruit. These results signifies that suggests that modified atmosphere created by 
edible coating has not promoted the biosynthesis of theses secondary metabolites during storage.

\subsubsection{The 2, 2-diphenyl-1-picrylhydrazyl (DPPH) scavenging activity and reducing} power

The DPPH scavenging activity of uncoated and coated fruit samples are shown in table 1. Scavenging activity was reported to decline with ripening (Sivakumar et al., 2012) and similar behavior was observed in this study in the case of uncoated fruit. However, the application of rice starch coating improved the retention of scavenging activity of plum fruit stored at $20^{\circ} \mathrm{C}$. A correlation between CUPRAC and TFC $\left(\mathrm{R}^{2} 0.86\right)$ at the $0.05 \%$ level was observed during the storage study of plum fruit signifying that total antioxidant activity was significantly influenced by the flavonoid content of the fruit $(p<0.05)$. On the contrary, no significant influence was found between flavonoids and free radical scavenging activity where a moderate correlation was observed $(p>0.05)$ and a moderate correlation between TFC and DPPH $\left(\mathrm{R}^{2} 0.36,0.05 \%\right)$. The phytochemical profile is different in other fruit as reported by Kim et al. (2007) who found that scavenging activity was influenced by the flavonoids content in the fruit.

\section{Conclusion}

Results presented in this study demonstrated that RS-1-car-FAEs delayed the increase in respiration rate and inhibiting the ethylene production. Control fruit lost marketability within two weeks of storage due to loss of firmness while coated plums remained firm with good color for up to three weeks at room temperature for coated plums. The delay in ripening was also reflected in accumulation of phytochemicals and the concentration of phenolics, 
422 flavonoids was higher at the end of storage period. However, more future study is required to 423 elucidate the enzymatic mechanisms involved in the delay in ripening behavior of plum fruit.

\section{Acknowledgement}

425 This work was supported by the University of Newcastle, Australian Research Council 426 (ARC) Training Centre for Food and Beverage Supply Chain and Optimisation 427 (IC140100032). NSW Department of Primary Industries is a partner organisation in the 428 training centre. We greatly acknowledge University of Newcastle EMX unit, for providing 429 access to SEM and XRD instruments.

430 Authors declare no conflict of interest. 
Andrade, S.C.A., Baretto, T.A., Arcanjo, N.M.O., Madruga, M.S., Meireles, B., Cordeiro, Â.M.T., Barbosa de Lima, M.A., de Souza, E.L., Magnani, M., 2017. Control of Rhizopus soft rot and quality responses in plums (Prunus domestica L.) coated with gum arabic, oregano and rosemary essential oils. Journal of Food Processing and Preservation, e13251-n/a. Arnon, H., Granit, R., Porat, R., Poverenov, E., 2015. Development of polysaccharides-based edible coatings for citrus fruits: A layer-by-layer approach. Food Chemistry 166, 465-472. Baldwin, E.A., Burns, J.K., Kazokas, W., Brecht, J.K., Hagenmaier, R.D., Bender, R.J., Pesis, E., 1999. Effect of two edible coatings with different permeability characteristics on mango (Mangifera indica L.) ripening during storage. Postharvest Biology and Technology 17, 215-226. Bhuyan, D.J., Van Vuong, Q., Chalmers, A.C., van Altena, I.A., Bowyer, M.C., Scarlett, C.J., 2015. Microwave-assisted extraction of Eucalyptus robusta leaf for the optimal yield of total phenolic compounds. Industrial Crops and Products 69, 290-299.

Bierhals, V.S., Chiumarelli, M., Hubinger, M.D., 2011. Effect of Cassava Starch Coating on Quality and Shelf Life of Fresh-Cut Pineapple (Ananas Comosus L. Merril cv "Pérola"). Journal of Food Science 76, E62-E72.

Both, V., Thewes, F.R., Brackmann, A., Ferreira, D.d.F., Pavanello, E.P., Wagner, R., 2016. Effect of low oxygen conditioning and ultralow oxygen storage on the volatile profile, ethylene production and respiration rate of 'Royal Gala' apples. Scientia Horticulturae 209, 156-164.

Brasil, I.M., Siddiqui, M., 2018. Chapter 1 - Postharvest Quality of Fruits and Vegetables: An Overview, Preharvest Modulation of Postharvest Fruit and Vegetable Quality. Academic Press, pp. 140.

Chiumarelli, M., Pereira, L.M., Ferrari, C.C., Sarantópoulos, C.I.G.L., Hubinger, M.D., 2010. Cassava Starch Coating and Citric Acid to Preserve Quality Parameters of Fresh-Cut "Tommy Atkins" Mango. Journal of Food Science 75, E297-E304.

Choi, W.S., Singh, S., Lee, Y.S., 2016. Characterization of edible film containing essential oils in hydroxypropyl methylcellulose and its effect on quality attributes of 'Formosa' plum (Prunus salicina L.). LWT - Food Science and Technology 70, 213-222.

Deng, Z., Jung, J., Simonsen, J., Zhao, Y., 2017. Cellulose nanomaterials emulsion coatings for controlling physiological activity, modifying surface morphology, and enhancing storability of postharvest bananas (Musa acuminate). Food Chemistry 232, 359-368.

Dongen, J.T.v., Licausi, F., 2015. Oxygen Sensing and Signaling. Annual Review of Plant Biology 66, 345-367.

Fagundes, C., Palou, L., Monteiro, A.R., Pérez-Gago, M.B., 2015. Hydroxypropyl methylcellulosebeeswax edible coatings formulated with antifungal food additives to reduce alternaria black spot and maintain postharvest quality of cold-stored cherry tomatoes. Scientia Horticulturae 193, 249257.

García, M.A., Martino, M.N., Zaritzky, N.E., 2001. Composite starch-based coatings applied to strawberries (Fragaria ananassa). Food / Nahrung 45, 267-272.

Ghasemnezhad, M., Zareh, S., Rassa, M., Sajedi, R.H., 2013. Effect of chitosan coating on maintenance of aril quality, microbial population and PPO activity of pomegranate (Punica granatum L. cv. Tarom) at cold storage temperature. Journal of the Science of Food and Agriculture 93, 368374.

Guillén, F., Díaz-Mula, H.M., Zapata, P.J., Valero, D., Serrano, M., Castillo, S., Martínez-Romero, D., 2013. Aloe arborescens and Aloe vera gels as coatings in delaying postharvest ripening in peach and plum fruit. Postharvest Biology and Technology 83, 54-57.

Huc, D., Matignon, A., Barey, P., Desprairies, M., Mauduit, S., Sieffermann, J.M., Michon, C., 2014. Interactions between modified starch and carrageenan during pasting. Food Hydrocolloids 36, 355480 361. 
Hussain, P.R., Suradkar, P.P., Wani, A.M., Dar, M.A., 2015. Retention of storage quality and postrefrigeration shelf-life extension of plum (Prunus domestica L.) Cv. Santa Rosa using combination of carboxymethyl cellulose (CMC) coating and gamma irradiation. Radiation Physics and Chemistry 107, 136-148.

Jatoi, M.A., Juric, S., Vidrih, R., Vincekovic, M., Vukovic, M., Jemric, T., 2017. The effects of postharvest application of lecithin to improve storage potential and quality of fresh goji (Lycium barbarum L.) berries. Food Chem 230, 241-249.

Karaca, H., Pérez-Gago, M.B., Taberner, V., Palou, L., 2014. Evaluating food additives as antifungal agents against Monilinia fructicola in vitro and in hydroxypropyl methylcellulose-lipid composite edible coatings for plums. Int. J. Food Microbiol. 179, 72-79.

Kim, I.-H., Lee, H., Kim, J.E., Song, K.B., Lee, Y.S., Chung, D.S., Min, S.C., 2013. Plum Coatings of Lemongrass Oil-incorporating Carnauba Wax-based Nanoemulsion. Journal of Food Science 78, E1551-E1559.

Kim, Y., Brecht, J.K., Talcott, S.T., 2007. Antioxidant phytochemical and fruit quality changes in mango (Mangifera indica L.) following hot water immersion and controlled atmosphere storage. Food Chemistry 105, 1327-1334.

Kowalczyk, D., Kordowska-Wiater, M., Zięba, E., Baraniak, B., 2017. Effect of carboxymethylcellulose/candelilla wax coating containing potassium sorbate on microbiological and physicochemical attributes of pears. Scientia Horticulturae 218, 326-333.

Kumar, P., Sethi, S., Sharma, R.R., Srivastav, M., Varghese, E., 2017. Effect of chitosan coating on postharvest life and quality of plum during storage at low temperature. Scientia Horticulturae 226, 104-109.

Lascombes, C., Agoda-Tandjawa, G., Boulenguer, P., Le Garnec, C., Gilles, M., Mauduit, S., Barey, P., Langendorff, V., 2017. Starch-carrageenan interactions in aqueous media: Role of each polysaccharide chemical and macromolecular characteristics. Food Hydrocolloids 66, 176-189. Liu, K., Yuan, C., Chen, Y., Li, H., Liu, J., 2014. Combined effects of ascorbic acid and chitosan on the quality maintenance and shelf life of plums. Scientia Horticulturae 176, 45-53.

Mahfoudhi, N., Hamdi, S., 2015. Use of Almond Gum and Gum Arabic as Novel Edible Coating to Delay Postharvest Ripening and to Maintain Sweet Cherry (Prunus avium) Quality during Storage. Journal of Food Processing and Preservation 39, 1499-1508.

Manjunatha, G., Lokesh, V., Neelwarne, B., 2010. Nitric oxide in fruit ripening: Trends and opportunities. Biotechnology Advances 28, 489-499.

Martínez-Romero, D., Zapata, P.J., Guillén, F., Paladines, D., Castillo, S., Valero, D., Serrano, M., 2017. The addition of rosehip oil to Aloe gels improves their properties as postharvest coatings for maintaining quality in plum. Food Chemistry 217, 585-592.

Mditshwa, A., Magwaza, L.S., Tesfay, S.Z., Mbili, N., 2017. Postharvest quality and composition of organically and conventionally produced fruits: A review. Scientia Horticulturae 216, 148-159.

Minas, I.S., Crisosto, G.M., Holcroft, D., Vasilakakis, M., Crisosto, C.H., 2013. Postharvest handling of plums (Prunus salicina Lindl.) at $10^{\circ} \mathrm{C}$ to save energy and preserve fruit quality using an innovative application system of 1-MCP. Postharvest Biology and Technology 76, 1-9.

Nadim, Z., Ahmadi, E., Sarikhani, H., Amiri Chayjan, R., 2015. Effect of Methylcellulose-Based Edible Coating on Strawberry Fruit's Quality Maintenance During Storage. Journal of Food Processing and Preservation 39, 80-90.

Pan, H., Wang, L., Wang, R., Xie, F., Cao, J., 2018. Modifications of cell wall pectin in chilling-injured 'Friar' plum fruit subjected to intermediate storage temperatures. Food Chemistry 242, 538-547. Pan, H., Wang, R., Li, L., Wang, J., Cao, J., Jiang, W., 2016. Manipulation of ripening progress of different plum cultivars during shelf life by post-storage treatments with ethylene and 1methylcyclopropene. Scientia Horticulturae 198, 176-182.

Paniagua, A.C., East, A.R., Hindmarsh, J.P., Heyes, J.A., 2013. Moisture loss is the major cause of firmness change during postharvest storage of blueberry. Postharvest Biology and Technology 79, 13-19. 
Šamec, D., Maretić, M., Lugarić, I., Mešić, A., Salopek-Sondi, B., Duralija, B., 2016. Assessment of the differences in the physical, chemical and phytochemical properties of four strawberry cultivars using principal component analysis. Food Chemistry 194, 828-834.

Singh, S.P., Singh, Z., Swinny, E.E., 2009. Postharvest nitric oxide fumigation delays fruit ripening and alleviates chilling injury during cold storage of Japanese plums (Prunus salicina Lindell). Postharvest Biology and Technology 53, 101-108.

Sivakumar, D., Van Deventer, F., Terry, L.A., Polenta, G.A., Korsten, L., 2012. Combination of 1methylcyclopropene treatment and controlled atmosphere storage retains overall fruit quality and bioactive compounds in mango. Journal of the Science of Food and Agriculture 92, 821-830. Tesfay, S.Z., Magwaza, L.S., 2017. Evaluating the efficacy of moringa leaf extract, chitosan and carboxymethyl cellulose as edible coatings for enhancing quality and extending postharvest life of avocado (Persea americana Mill.) fruit. Food Packaging and Shelf Life 11, 40-48.

Thakur, R., Pristijono, P., Golding, J.B., Stathopoulos, C.E., Scarlett, C., Bowyer, M., Singh, S.P., Vuong, Q.V., 2018. Effect of starch physiology, gelatinization, and retrogradation on the attributes of rice starch-t-carrageenan film. Starch - Stärke 70, 1700099.

Thakur, R., Saberi, B., Pristijono, P., Golding, J., Stathopoulos, C., Scarlett, C., Bowyer, M., Vuong, Q., 2016. Characterization of rice starch-iota-carrageenan biodegradable edible film. Effect of stearic acid on the film properties. Int J Biol Macromol 93, 952-960.

Thakur, R., Saberi, B., Pristijono, P., Stathopoulos, C.E., Golding, J.B., Scarlett, C.J., Bowyer, M., Vuong, Q.V., 2017. Use of response surface methodology (RSM) to optimize pea starch-chitosan novel edible film formulation. Journal of Food Science and Technology, 1-9.

Valero, D., Díaz-Mula, H.M., Zapata, P.J., Guillén, F., Martínez-Romero, D., Castillo, S., Serrano, M., 2013. Effects of alginate edible coating on preserving fruit quality in four plum cultivars during postharvest storage. Postharvest Biology and Technology 77, 1-6.

Vargas-Torres, A., Becerra-Loza, A.S., Sayago-Ayerdi, S.G., Palma-Rodríguez, H.M., García-Magaña, M.d.L., Montalvo-González, E., 2017. Combined effect of the application of 1-MCP and different edible coatings on the fruit quality of jackfruit bulbs (Artocarpus heterophyllus Lam) during cold storage. Scientia Horticulturae 214, 221-227.

Wills, R., Golding, J., 2016. Postharvest: An introduction to the physiology and handling of fruit and vegetables, 6th edition. UNSW Press.

Wu, F., Zhang, D., Zhang, H., Jiang, G., Su, X., Qu, H., Jiang, Y., Duan, X., 2011. Physiological and biochemical response of harvested plum fruit to oxalic acid during ripening or shelf-life. Food Research International 44, 1299-1305. 